\title{
Language Trends in Social Media: Manifestations of Meranaws' Use of English on Facebook ${ }^{*}$
}

\author{
Sorhaila Latip-Yusoph \\ Mindanao State University, Marawi City, Philippines
}

\begin{abstract}
As a major new means of global communication, social media platforms such as Facebook have afforded linguists of today to observe the development and diffusion of a language online. This study looked into the dominant language use seen in the Facebook profiles of the Meranaw professionals and their reasons given for the use of English as a language in their posts. Further, using Netnography, a form of Internet ethnography, dominant language present in the reactions of Facebook friends to the researchers' most commented post was observed in order to identify the dominant language in support to the profile observations with the participants. Results showed two interesting findings that have emerged from this netnographic research and virtual interview. First, English is the dominant language used by the selected participants in the observation made from October to November 2015 and the comment posts made by the FB friends of the researcher during the said observation. Second, among the identified reasons for posting in English, the majority of the responses were because of English's global/universal use that allows all audiences to understand the posts made by the participants and followed by the comfortability or confidence of the participant over the use of English as a language in their posts. In addition, the researcher believed that "language is culture". The minimal use of the Meranaw language implied a minimal presence of the cultural idiosyncrasies of the Meranaws on social media platforms. Hence, when a closer and longer look at the language use is done, a clearer picture of the cultural idiosyncrasies of the Meranaws may be visible in the posts even with the use of English language. In that light, it is worthwhile to consider whether the online use of English and Meranaw by this small group of Meranaw professionals might reflect broader and more enduring social, cultural, and linguistic shifts.
\end{abstract}

Keywords: language use, social media, Facebook, language choice, Meranaw

\section{Introduction}

In the recent statistics of 2015 by Internet World Stats, different languages around the globe at 693.9 million users have become visible online. However, English is still the dominant language and has the largest statistic at 851.6 million users online. Hence, it dominates the web content including social media networking sites.

\footnotetext{
${ }^{*}$ Acknowledgements: It has to be acknowledged that the friends of the researchers are the participants of this research. Further, it has to be acknowledged that those 30 participants were cooperative enough to respond to the question raised for this study. Acknowledgement is due also to the advent of social media. Because of this platform, the study using netnography and virtual interview will not be this useful for budding researchers like us in this highly globalized and interconnected world.

Sorhaila Latip-Yusoph, Ph.D. candidate, Language Studies, CSSH, MSU-Marawi.
} 
Since the Internet is the new means to global interaction, English language use as a field of interest has significantly heightened. English is said to have crowded out all other languages because of its dominance on the Internet. In fact, English remains even more dominant in most internet realm. In the study conducted by the Organization for Economic Cooperation and Development (OECD, 1999, as cited in Warchauser, Said, and Zohry, 2007), they found that $91 \%$ of the websites on "secure servers" were in English, and $96 \%$ is found in other domains.

Because of the influence of English as a language, it has become an interest to every linguist to study this dominance. As how Crystal (2011) puts it, "Wherever we find language, we find linguists". The strong presence of English online has caused trepidation among many (Warchauser, Said, and Zohry, 2007) especially to multilinguals around the globe who promote national languages like the Filipinos.

Nonetheless, despite the dominance present online, this aspect of research has not been fully explored especially by and among Filipinos who are known to have many languages from childhood.

Hence, in this research, the focus is on the use of English among Meranaws online since it has been evident in the social networking sites used by the Meranaws on Facebook. In fact, Latip-Yusoph (2015) argued in her study on language in the virtual social networks that English is still the dominant language despite the use of other languages online.

Moreover, in most instances where the researcher had the chance to informally ask about the importance of English to Meranaws, most of the responses include "prestige" of the language and that to be able to speak the English language is an edge over others. This may be the reason why even on the linguistic landscape of the Meranaws, English is still the dominant language used in the tarpaulins printed for community horizontal communication process (Latip-Yusoph, 2015).

Hence, this present research sees the relevance of further looking at the influence of English and the purpose of the users in using English on their Facebook posts and not their mother-tongue. To achieve this purpose, this study shall answer the following questions, to wit:

(1) What is the dominant language seen in the Facebook profiles of the participants?

(2) From the observed Facebook friends, what are the reasons given by the users in their use of English as a language in their posts?

(3) Aside from the posts, what is the dominant language present in the reactions of Facebook friends to the researchers' most commented post?

Significantly, this simple study served as an inspiration of the researcher to further her study about the relevant influence of online media use in the identity and culture of the Meranaws. Since the researcher believes in the idea of "Language is equal to culture", she sees the changes in language exposure and use among Meranaws as manifestations of cultural shifts and possibly, cultural divergence if not cultural deterioration of the Meranaw culture.

\section{Literature Review}

To enhance the background of this study and to give more contextual information, the language context and the social media context of the Meranaws were presented and discussed below. 


\section{Language Context of the Meranaws}

Language use in Lanao is an example of multilingualism. Children at their very young age started to learn at least two languages (e.g., Meranaw and Tagalog); then they get to learn at least one auxiliary language (e.g., Bisaya or Iranun) depending on the geographical area where they live (Latip-Yusoph, 2011).

Observed and experienced by the researcher, Meranaw, as a language, is an oral language by nature that uses two varieties. These are referred to as classical Meranaw and the colloquial Meranaw. Aside from this, there are sub-dialects of this language. Meranaws living near the sea (Lanao Norte) are having a different dialect called "Meragat" where some words are not known to the Meranaws in Lanao del Sur. Even among people in Lanao del Sur, there are differences in the sub-dialects between people from mainland and those from hinterlands.

Nonetheless, both Meranaw varieties (classical and colloquial) have their own powerful use in the daily language use of the people. The classical Meranaw is considered as the language of the Darangen, the Meranaw Epic and the one used for formal occasions such as wedding salsilah, royal house coronations, and the like. While the colloquial Meranaw is the variety understood by many especially the youth and the ones used by media communicators on radio and TV in order to be understood.

Beyond these varieties, English serves as the second language that is well recognized by the people of Lanao. In fact, in the recent research made on the linguistic landscape of Marawi by Latip-Yusoph (2015), English is the dominant language found on the linguistic landscape of Marawi especially on Marawi newspaper, tarpaulins, and store names. Further, majority of the private schools in Marawi are forwarding English only policy (EOP) in order to enhance and practice the students in the use of English as a second language. In the university, if one graduates, he will be given a certification that Mindanao State University is a university using English as a medium of instruction. These facts contributed to the strength of English language use among Meranaws.

Recently, through the efforts of the Meranaw linguists, the term "Meranaw" has now been widely accepted after the approval made by the Komision ng Wikang Filipino (2014). The commission is still on its way to approve all the proposals for the proper orthography of the Meranaw language. This justifies the reason why the language has become an oral language and not the language used in most of the formal written documents of the Meranaws. This can further support why English is considered as the language of the educated Meranaws because of the absence of the orthography for centuries now.

In the different literatures written about the Meranaw as a language, Laubach, an American researcher in Lanao attempted to write a dictionary in 1933 and 1948, but it was never published (see iloko.tripod.com/Maranao). The next effort was by B. Macaraya and E. Macaraya (1991) who made a list of Meranao words and phrases. None of these efforts authenticated the formal written alphabet, and spellings continue to be debated. Even the term Meranao, used by Meranao professionals, has been rendered variously as Maranao or Maranaw in other literature. For purposes of this study, Meranao (with an "e" as the closest representation of the pepet (central vowel) sound in all words listed in the literature), is used to refer to the language. Lobel and Riwarung (2011) described it:

The Meranao (Maranao) Language is an Austronesian language of the Greater Central Philippine subgroup spoken primarily on the southern Philippine island of Mindanao in the provinces of Lanao del Sur and Lanao del Norte. Native speakers identify themselves and their language as Meranao/Maranao [m(ə)ranaw]. The 2000 population estimate for the Meranao was over one million. (p. 2) 
Nonetheless, aside from the Meranaw language, Meranaws in Lanao province are influenced by the educational system of the Autonomous Region in Muslim Mindanao (ARMM), in which Arabic is taught in schools for Muslims as the language of religion (DepED Order No. 51, s. 2004, by virtue of ARMM RG Executive Order No. 13-A, s. 2004). Consequently, a Meranaw child who begins school at age seven knows the indigenous Meranaw language, Bisaya as the regional lingua franca, Filipino and English as the official languages in school and Arabic as the language of religion. One can see, therefore, how Filipino Meranaws can have five languages at play in any linguistic domain.

\section{Social Media and the Context of the Meranaws}

Technological progress in the 21 st century has introduced millions of people in the world to the Internet. Access to the Internet has caused an exponential growth of communication among individuals who engage daily in evolving virtual social networks. In the study done by Leeming and Danino (2014), they cited that in the Facebook API of 2011, the Philippines is the 7th country in the top 30 countries with highest number of users. While in the Socialbakers.com (2011), Philippines rank second in Asia. This development has opened new avenues for linguists to explore the languages involved in interactions on social networks. As Crystal (2011) puts it: "Wherever we find language, we find linguists... [They] seek out, describe and analyse manifestations of language everywhere...”(p. 1). Mundane interactions between young and old alike have been made available via the virtual communities created on social networks.

Since the Philippines is considered a country with Multilingual speakers, it is expected that their languages will be evident in the social media platform that we will see. Indeed, this virtual social network (VSN) online offers a new means of communication using text and various other media in cyberspace (Panteli, 2009).

In the Philippines, there is this free Facebook and Twitter services provided by different networks. Hence, any person connected to these social media platforms will have the chance to collaborate and communicate online. These include the ability of the Meranaws to use these platforms because of the connectivity that they have in Lanao del Sur. Both Smart and Globe services are available in the area, not to mention other telecommunication services (e.g., TM, SUN, and TNT).

On a broader context, social media context in the Philippines and the whole world is powered by the Internet. Because of the advent of computer mediated communication, languages used in communication became an interest to all linguists. As defined, Computer mediated communication (CMC), Santoro (1995), Herring (1996 and 2007) and December (1997), Thurlow, Lengel and Tomic (2004) is the predominantly text-based human-human interaction that takes place in a mediated network of computers or mobile telephones that allow a process of communication in different contexts and purposes.

Further, CMC is defined by Wood and Smith (2005) as a new field for the study of human behaviors as they are maintained or altered by the exchange of information through machines like computers. They argued that $\mathrm{CMC}$ focuses on the "channels of communication made possible by the Internet, where human beings exert individual will, conduct business, and form communities" (Wood \& Smith, 2005).

CMC can include any communication through email, online news, online chatting, social network posts, forum comments, etc. (Crystal, 2004). In each venue, different modes of online communication may occur, called synchronous and asynchronous $\mathrm{CMC}$, depending on whether the interaction takes place in real time or when 
participants are not online simultaneously (Simpson, 2002). Synchronous CMC includes online chats while asynchronous includes email and social network posts.

These characteristics of CMC as defined above became useful to all users including the Meranaws. Latip-Yusoph's article on the use of virtual social network of the teachers and students argued that use of Facebook among Meranaws is the top virtual social network used (Latip-Yusoph, 2015).

\section{Research Methods}

Since this study will look at the language in a computer-mediated communication context, the appropriate methodology to gather the data regarding language choice of the Meranaws will be a combination of Netnography and Virtual Individual Interview.

Netnography (Kozinets, 2002) is used to study people's social activities and encounters onto the Internet and through other technologically-mediated communications to discover current uses of social media for communities. Since Meranaws are using Facebook as the platform for social media interactions, the netnographic research is supported by a virtual interview whereby selected participants are given a general question as to why they prefer one language over the other (e.g., English over Meranaw). The observation period was done from October to November 2015. In early October, the chosen participants were asked why they prefer to post in English and not Meranaw or any other mother-tongue based languages.

\section{Participants}

Since this study was done online, the participants/respondents were the chosen 30 Meranaws who were online on the particular date that the netnography was done (October to November 2015). Since this study is used for academic use only, the respondents were informed that their names will be highly confidential as they are presented in this study. Further, the observation and the gathering of the corpus from the posts made by the respondents were collected for content analysis to identify the most commonly used language in their posts and profiles.

Hence, this study is carried out among 30 Meranaw professionals online who are members of Facebook and are friends with the researcher. Of the 30,19 of them are females and 11 are males. These 30 participants are all working in different institutions all over the Philippines. Since this study does not include demographic profiles as variables affecting the language choice, the study described only those that are observed in their individual posts on Facebook from October to November 2015.

To answer research question number three, participants of the coded languages used will be based on the responses of the different reactors in the post made by the author during the netnography month (October to November 2015). These participants may be inclusive of the above participants but may also include other reactors.

\section{Limitations}

It is important to point out the limitations of this study. The sample is small and non-random, having been selected through personal contacts of the researcher. The interview was based on the dominantly seen language on the Facebook feed of the researcher. The responses to the general question was not coded but was used for purposes of triangulating the purpose of use of the dominant language. For all of these reasons, the result of the study cannot be assumed to be generalizable to other populations beyond this group of participants. Rather, this was an exploratory investigation to identify possible issues and trends for further research. 


\section{Results}

The most interesting result of this netnographic and virtual interview is the language use dominance and choice of the Meranaws on Facebook. Using the research problem, the results are presented accordingly. The research questions were:

(1) What is the dominant language seen in the Facebook profiles of the participants?

(2) From the observed Facebook friends, what are the reasons given by the users in their use of English as a language in their posts?

(3) Aside from the posts, what is the dominant language present in the reactions of Facebook friends to the researchers' most commented post?

\section{Dominant Language on the Facebook Profile}

Monolingual posts. There are four dominant languages used by the Meranaw professionals in their monolingual posts. However, most of the participants are dominantly posting in English. Most of the posts made are written in English as shown in Table 1 below.

Table 1

Average Number of Posts Used in a Particular Language

\begin{tabular}{lll}
\hline Language & Average posts & Percentage \\
\hline Meranaw & 2 & $5.88 \%$ \\
Arabic & 4 & $11.76 \%$ \\
English & 17 & $50.00 \%$ \\
Tagalog/Filipino & 6 & $17.65 \%$ \\
Others (e.g., Bisaya) & 5 & $14.71 \%$ \\
Total & 34 & $100 \%$ \\
\hline
\end{tabular}

From the above data, there are sample screen shots of the dominance of such language in the profiles of the Meranaw professionals below:

English dominant posts. From formal posts to informal posts, you can see how the English language is used in their profile pages.

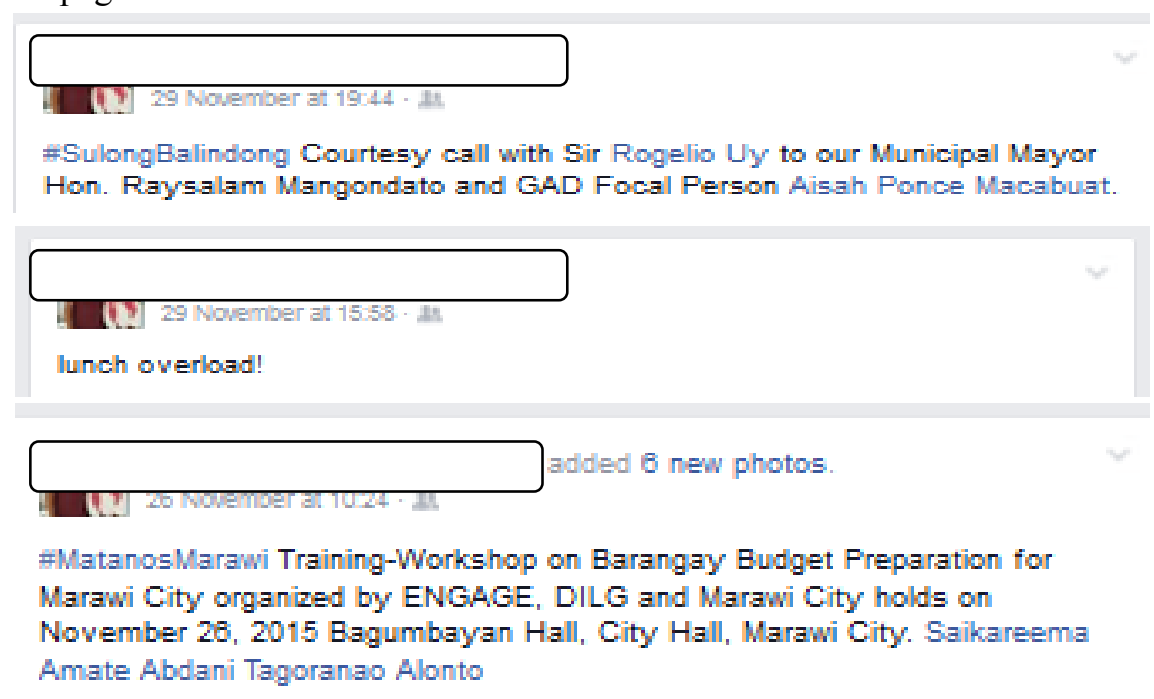

Figure 1. (Right) Sample profile posts for a sample participant. 
Multilingual posts. In the posts made by Meranaws, there are certain posts that use more than one language in one post. Dominantly, it is the combination of an Arabic word (e.g., Alhamdulillah) with other English statements. Table 2 below shows the average number of posts using two or more languages. On the other hand, there are certain posts that are posted with three languages combined in one post. There may be few but they are present in the corpus collected. The distribution is seen in Table 3 below.

Table 2

Average Multilingual Posts With Two Languages Combined

\begin{tabular}{lll}
\hline Two languages combined & Average posts & Percentage \\
\hline Tagalog-English & 13 & $30.23 \%$ \\
Meranaw-English & 5 & $11.63 \%$ \\
Meranaw-Tagalog & 3 & $6.98 \%$ \\
Arabic-English & 17 & $39.53 \%$ \\
Bisaya-English & 2 & $4.65 \%$ \\
Tagalog-Arabic & 3 & $6.98 \%$ \\
Total & 43 & $100 \%$ \\
\hline
\end{tabular}

From the above table, the dominant combination for bilingual posts is Arabic-English with 17 average posts. In this combination, most of the Arabic words are just expressions usually used by Muslims in appreciating Allah (Alhamdulillah and Ma Shaa Allah) and when the greatness of God is mentioned (Allahu Akhbar) or when one wishes for God's will (In Shaa Allah).

Below is Table 3 showing average multilingual posts with three languages used in the combination.

Table 3

Average Multilingual Posts With Three Languages Combined

\begin{tabular}{lll}
\hline Three languages combined & Average posts & Percentage \\
\hline Meranaw-Tagalog-English-comb & 15 & $71.40 \%$ \\
Tagalog-English-Arabic-comb & 2 & $9.50 \%$ \\
Bisaya-English-Tagalog & 2 & $9.50 \%$ \\
Meranaw-English-Arabic-comb & 1 & $4.80 \%$ \\
Total & 21 & $100 \%$ \\
\hline
\end{tabular}

As shown, the dominant combination for trilingual posts is Meranao-Tagalog-English with 15 of 21 trilingual posts. Though the total number of trilingual posts (21) is very low, the occurrence of three languages combined in the posts is evident in this data.

\section{Reasons for English Language Use}

Aside from the observation made by the researcher using Netnography, the researcher asked a general question to all of the chosen participants regarding their use of the English language as the dominant language used in their posts. Based on their responses, the following are the coded classifications made as they appear. 
Table 4

Coded Responses on "Why English Is Preferred"

\begin{tabular}{lll}
\hline Coded responses* & Number of responses & Rank \\
\hline Strengthen English Skills & 4 & 3 \\
Comfortable/Confident in expressing ideas & 13 & 2 \\
Difficulty in Meranaw language & 3 & 4 \\
Social media norm & 3 & 4 \\
Understandable to audience & 15 & 1 \\
Project being learned & 2 & 5 \\
Lesser comments & 1 & 6 \\
Global/Universal language & 4 & 3 \\
\hline
\end{tabular}

Note. * Multiple responses.

From the above result, it shows that more of the audience would like to use English because it is more understandable to any type of Audience. It is clearly true that when we use online platforms as seen on different surveys, English is becoming the dominant language.

In this type of response, below is a figure that expresses the said reason:

\section{Samples of Responses on Print Screen}

Using print-screen of the computer, the following responses to the interview question are presented below for further evidence of responses made by the participants.

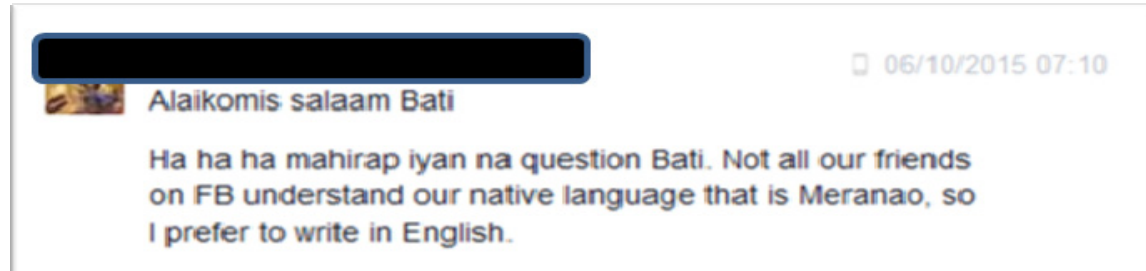

Figure 2. English is more understood.

Aside from being understood by many Facebook users, English is preferred according to the participants because of it can easily be expressed and is comfortable to users. The print screen of a response below shows both of possible reasons.

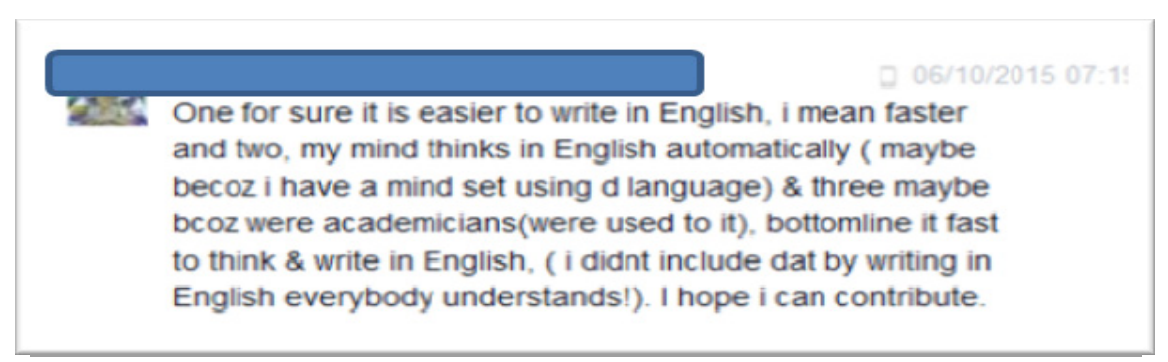

Figure 3. English is more comfortable and understood.

\section{Dominant Language on Comment Posts}

Aside from the responses on the interview question, the researcher further used Netnography as a method to observe and code the languages used in the comment posts of the Facebook friends of the researcher when a photo 
was posted about the nomination for "Columnist of the Year" of the researcher. For purposes of having an ample number of responses, the researcher chose this post for it is the highly commented post during the month of the observation. Then, the languages used in the posts were coded according to languages used. Table 5 below shows the breakdown of the languages used. Figure 3 then follows for the print screen of the sample comment posts.

Table 5

Languages Used by Reactors

\begin{tabular}{llll}
\hline Language & Number of comments & Percentage & Rank \\
\hline Arabic + English combination & 14 & $30.43 \%$ & 2 \\
Arabic only & 1 & $2.17 \%$ & 4 \\
Bisaya + English combination & 1 & $2.17 \%$ & 4 \\
English only & 26 & $56.52 \%$ & 1 \\
Tagalog + English combination & 4 & $8.71 \%$ & 3 \\
Total & 46 & $100 \%$ & \\
\hline
\end{tabular}

From the above table, the dominance again of English on comment posts is highly visible. In fact, even on the Arabic-English combination, English is still dominating the sentential switch. In the print screens below, you will see how English sentences are combined with the Arabic words/ expressions such as Alhamdulillah, Ma Shaa Allah, etc.

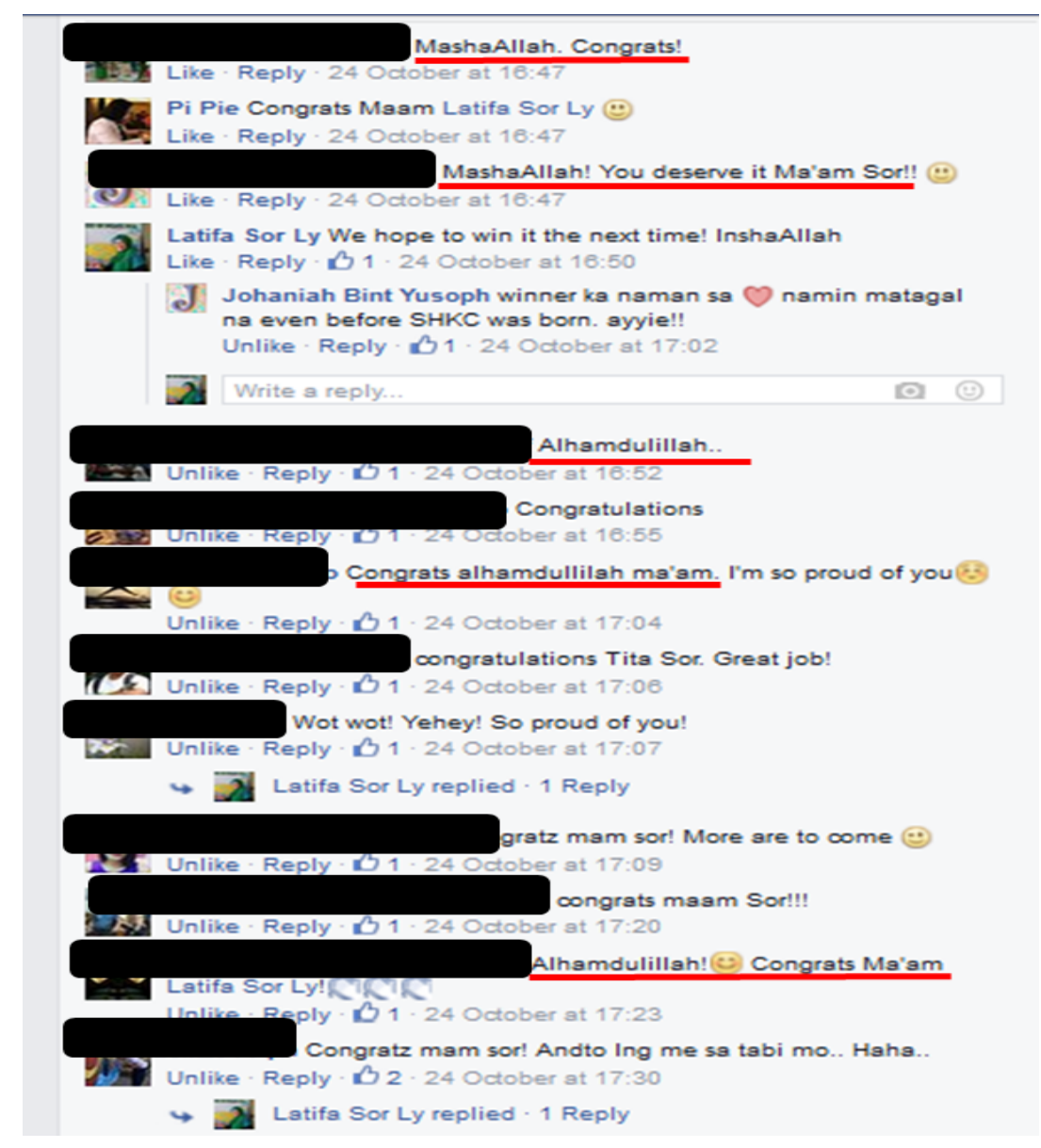

Figure 4. Sample thread with Arabic and English combined sentences. 
As shown in the above figure (print-screenshot), we can see how English has become dominant in the comment posts despite the presence of the Arabic words and expressions. This shows how English has become the dominant language in the said posts observed by the researcher.

\section{Discussion}

Two interesting findings emerged from this netnographic research and virtual interview: First, that English is the dominant language used by the selected participants in the observation made from October to November 2015 and the comment posts made by the FB friends of the researcher during the said observation, and second, that among the identified reasons for posting in English, the majority of the responses were because of English's global/universal use that allows all audiences to understand the posts made by the participants and followed by the comfortability or confidence of the participant over the use of English as a language in their posts. However, the researcher would like to argue that the meaning of these findings is better understood when examined in a broader context of language, technology, and society within the Meranaws and even other cultural groups. The length of the observation may also bear a difference in the result once it is done over a longer period.

Interestingly, despite the majority of the reasons, there are those who claimed that English language use on posts allows the participants to strengthen their English language skills. As Godwin-Jones (as cited in Leeming \& Danino, 2014) mentioned in his study, he observes that tools and platforms such as Facebook enhance one's communication and human interaction that eventually harness language learning. It can further be inferred that this social media platform enhances the ability of a Meranaw to express him/herself in English and be understood by other cultural groups.

This study may serve as a prelude to further interesting research about the users' proficiency in the languages used for mixing. In fact, in the combination of English and Arabic expressions, we can claim that English is still the dominating language in the entire string of words. It can be inferred further that code-switching in different levels such as intrasentential, intersentential, and tag-switching are further observed. In most of the studies made by Filipino linguists, they have claimed how Filipinos have become confident in using code-switching. Bautista (2004), regarded Taglish phenomenon as an important mode of discourse and a language resource. She further argued that it could also be seen as an indicator of language degeneration. Hence, in this study made, the data here may be relevant: The higher percentage of two-language combination may imply ability to express in either languages or limited language ability in one language by the users.

If this trend continues, the consequence of this dominance of English and the minimal use of the Meranaw language in the online platforms may affect the way how Meranaw language is used and preserved. In fact, in the data, it can be argued that because of the absence of a systematic Meranaw orthography, the Meranaw users of social media platforms may continue to use English as a means to express their thoughts easily. This may become the norms among Meranaws online. This may be too early for the researcher to argue but the dominance of English eventually signifies a possibility of the Meranaw language to be totally absent in the online discourses of the Meranaws. There has to be immediate policy actions that should be done in order to enhance the preservation of native languages like Meranaw and other native languages.

\section{Conclusion}

Considering Facebook or any social media platform as an important communication medium, the Internet, 
whether we like it or not, will have a long term effect on our language use as a people. It may be too early to tell what the impact will be. However, if these trends continue, the development and diffusion of the English as a language among Meranaws will be more evident. Effects on the Meranaw language such as minimal use and the eventual inability of the new generation to use the language will eventually affect the fluency of the Meranaws of their own language.

Going back to the contention of the researcher that "language is culture", the minimal use of the Meranaw language implies a minimal presence of the cultural idiosyncrasies of the Meranaws on social media platforms. Possibly, when a closer and longer look at the language use is done, like a critical discourse analysis of the texts, a clearer picture of the cultural idiosyncrasies of the Meranaws may be visible in the posts even with the use of English language.

In that light, it is worthwhile to consider whether the online use of English and Meranaw by this small group of Meranaw professionals might reflect broader and more enduring social, cultural, and linguistic shifts.

\section{References}

Crystal, D. (2011). Internet linguistics: A student guide. Routledge: London.

Crystal, D. (2004). Language and the Internet. Cambridge: Cambridge University Press.

December, J. (1997). Notes on defining computer-mediated communication. CMC Magazine. Retrieved November 20, 2015 from http://www.december.com/cmc/mag/1997/jan/december.html

Herring, S. (2001). Computer-mediated discourse. In D. Tannen, D. Schiffrin, and H. Hamilton (Eds.), Handbook of discourse analysis (pp. 612-634). Oxford: Blackwell.

Herring, S. (1996). Introduction. In S. Herring (Ed.), Computer-mediated communication: Linguistic, social and cross-cultural perspectives (pp. 1-10). Amsterdam: Benjamins. Retrieved November 24, 2015 from http://ella.slis.indiana.edu/ herring/cmc.intro.1996.pdf

Kozinets, R. (2002). The field behind the screen: Using netnography for research. Retrieved from www.nyu.edu/classes/bkg/methods/netnography.pdf

Latip-Yusoph, S. (2015). Exploration of teachers' and students' attitude towards the integration of virtual social networks (VSN) in language learning classroom tasks. The International Journal Of Humanities \& Social Studies, 3(9), 228-235. Retrieved from http://theijhss.com/wp-content/uploads/2015/10/36.-HS1509-050.pdf

Latip-Yusoph, S. (2011). On screen: Language use and code-switching in a Facebook community by young multilingual Meranao Filipinos (Unpublished thesis, Cardiff University, United Kingdom).

Leeming, D. E., \& Danino, N. (2014). Breaking barriers: A case study of culture and facebook usage. Retrieved from https://www.researchgate.net/publication/259624472_Breaking_Barriers_A_Case_Study_of_Culture_and_Facebook_Usage

Lobel, W., \& Riwarung, L. (2011). Maranao: A preliminary phonological sketch with supporting audio. Language Conservation and Documentation, 5 (1), 31-59. Retrieved $\quad$ November 23, 2015 from http://scholarspace.manoa.hawaii.edu/bitstream/handle/10125/4487/000-lobelriwarung-nosound.pdf?sequence=397

Macaraya, B., \& Macaraya, E. (1991). Maranao words and phrases. Iligan City: Mindanao State University Research Center.

Pambansang Ortograpiya. (2014). Komision ng Wikang Filipino.

Panteli, N. (2009). Virtual social networks: Mediated, massive and multiplayer sites. UK: Palgrave and Macmillan.

Santoro, G. (1995). What is computer-mediated communication? In Z. Bergeand and M. Collins (Eds.), Computer mediated communication and the online classroom. New Jersey: Hampton.

Thurlow, C., Lengel, L., \& Tomic, A. (2004). Computer mediated communication: Social interaction and the Internet. London: Sage Publication Ltd..

Warschauer, M., El Said, G., \& Zohry, A. (2007). Language choice online. In B. Danet and S. Herring (Eds.), Multilingual Internet (pp.163-183). UK: Oxford University Press.

Wood, A., \& Smith, M. (2005). Online communication: Linking technology, identity and culture. London: Lawrence Erlbaum Associates Publishers. 